\title{
Author Correction: Priority effects in microbiome assembly
}

Reena Debray (D), Robin A. Herbert (D), Alexander L. Jaffe, Alexander Crits-Christoph, Mary E. Power and Britt Koskella (D)

Nature Reviews Microbiology (2021) https://doi.org/10.1038/s41579-021-00604-w Published online 27 August 2021

The reference highlight that should accompany reference 13 (Furman et al.) was printed under reference 130 (Lindemann et al.) in the article originally published online. This error has been corrected in the HTML and PDF versions of the article.

https://doi.org/10.1038/s41579-021-00643-3 I Published online 1 October 2021

(๑) Springer Nature Limited 202 